\title{
INSPIRASI ARSITEKTUR LOKAL TERHADAP BANGUNAN BUDAYA, KASUS DI CINA, NORWEGIA, DAN FINLANDIA UNTUK BANDUNG
}

\author{
Faradila $^{1, *}$, Maria Immaculata Ririk Winandari ${ }^{2}$, Sri Tundono ${ }^{3}$ \\ 1 Jurusan Arsitektur, Fakultas Teknik Sipil dan Perancangan, Universitas Trisakti, Jl. Kyai Tapa No.1, \\ RT.6/RW.16, Grogol, Kec. Grogol petamburan, Kota Jakarta Barat, Daerah Khusus Ibukota Jakarta, \\ 11440 , \\ 2Jurusan Arsitektur, Fakultas Teknik Sipil dan Perancangan, Universitas Trisakti, Jl. Kyai Tapa No.1, \\ RT.6/RW.16, Grogol, Kec. Grogol petamburan, Kota Jakarta Barat, Daerah Khusus Ibukota Jakarta, \\ 11440 \\ 3 Jurusan Arsitektur, Fakultas Teknik Sipil dan Perancangan, Universitas Trisakti, Jl. Kyai Tapa No.1, \\ RT.6/RW.16, Grogol, Kec. Grogol petamburan, Kota Jakarta Barat, Daerah Khusus Ibukota Jakarta, \\ 11440 \\ *faradila052001600083@std.trisakti.ac.id1
}

\begin{abstract}
ABSTRAK
Bangunan seni dan budaya sudah seharusnya merepresentasikan kawasan setempat. Representasi tersebut dapat dilakukan melalui berbagai pendekatan antara lain melalui arsitektur lokal atau setempat. Makalah ini mengeksplorasi arsitektur lokal yang digunakan untuk menginspirasi bangunan budaya di Cina, Norwegia, dan Finlandia serta penerapan dari ketiga kasus tersebut terhadap bangunan budaya di Bandung. Kasus studi terdiri dari tiga bangunan yaitu Flekkefjord Cultural Center di Norwegia, Shijiazhuang International Convention and Exhibition Center di Cina, dan Sami Cultural Center Sajos di Finlandia. Metode kualitatif melalui explorasi deskriptif terhadap ketiga kasus digunakan untuk mendapatkan inspirasi arsitektur lokal yang hasilnya diterapkan untuk bangunan budaya West Java Art and Cultural Center di Bandung. Variabel yang digunakan meliputi inspirasi bentuk tapak, inspirasi orientasi alam, dan inspirasi bentuk setempat yang dianalisis melalui gambar yang dibandingkan sebagai inspirasi bagi penerapan budaya di Bandung. Hasil memperlihatkan bahwa inspirasi arsitektur lokal dapat dilakukan melalui penyesuaian bentuk massa bangunan dengan bentuk tapak, penentuan arah hadap bangunan menghadap unsur alam di sekitar tapak serta pemilihan material yang mendukung orientasi atau arah hadap bangunan tersebut, dan penerapan bentuk lokal baik bangunan maupun pemilihan material yang sesuai dengan ketersediaan alam ke dalam bangunan. Hasil ini mendukung lokalitas bangunan modern di dalam kawasan dengan membawa unsur lokal dan alam ke dalam bangunan.
\end{abstract}

Kata kunci: arsitektur lokal, bandung, bangunan budaya. 


\begin{abstract}
Art and cultural center building mostly represents their environment. Art and cultural building uses varios architecture approach to suites the building and its environment. This paper explores local architecture that inspiring cultural center building in China, Norway, and Finland, and also its applications on cultural building in Bandung. Study cases consist of Flekkefjord Cultural Center, Shijiazhuang International Convention and Exhibition Center, and Sami Cultural Center Sajos. Using descriptive exploration method to find the inspiration of local architecture that will be use on West Java Art and Cultural Center in Bandung. Variables that use to analys is the inspiration of shape of site, the inspiration of nature orientation, and the inspiration of local form that will be analized by picturescomparison as inspiration for cultural building in Bandung. The results show local architecture inspiration can be applied by adjust building mass shape to the shape of site, the definition of direction on the building to local elements and building material that can supported the orientation of the building, and using local form of the building or the election of building material that represents local nature. This result can showed the locality of modern building in site by adjust local dan nature element to the building.
\end{abstract}

Keywords: Local Architecture, Bandung, Cultural Center.

\title{
PENDAHULUAN
}

Bangunan seni dan budaya pada umumnya merepresentasikan kawasan setempat. Bentuk bangunan seni budaya ini menggunakan berbagai pendekatan agar sesuai dengan kawasan tempat bangunan tersebut. Makalah ini mengeksplorasi arsitektur lokal yang menginspirasi bangunan budaya di Cina, Norwegia, dan Findlandia serta penerapan inspirasi tersebut ke bangunan budaya di Bandung. Ketiga bangunan seni budaya tersebut dibangun dengan mengusung unsur kebudayaan lokal ke dalam bangunan modern. Penerapan unsur bangunan lokal ke dalam bangunan modern diungkapkan Dabaieh, Makhlouf, \& Hosny (2016)bahwa penerapan struktur tradisional Mesir dapat menjadikan bangunan lebih hemat energi sementara Kırbaş \& Hızlı (2016) mengungkapkan penerapan arsitektur lokal meningkatkan kenyamanan di dalam bangunan modern. Wang, Li, \& Gan (2016) mengungkapkan tentang penerapan lokalitas arsitektur di Cina. Riset ini membahas mengenai bentuk tapak, orientasi alam, bentuk bangunan tradisional setempat, dan penerapan bentuk tradisional di ketiga kasus.

Menurut Fajrin \& Kurniawan (2018) bentuk tapak dan bangunan dapat menunjukkan lokalitas yang kontekstual dengan kawasan. Penentuan bentuk massa bangunan juga dapat mengadaptasi bentuk bangunan sekitar atau bangunan yang sudah terlebih dahulu ada di kawasan tersebut. Bentuk bangunan tradisional yang diterapkan pada bangunan akan membuat bangunan menjadi kontekstual terhadap kawasan. Orientasi alam bisa mempengaruhi bangunan seperti adanya wisata alam tertentu seperti pegunungan, sungai, laut, dan potensi alam lainnya yang bisa dikembangkan. Orientasi ini juga dapat 
mempengaruhi suhu bangunan serta kenyamanan pengunjung (Shareef, Omer, \& Maghdid, 2020). Bahkan di beberapa daerah sinar matahari dapat dijadikan orientasi alami bangunan (Mehrabi, 2016). Orientasi bangunan ini dapat mempengaruhi kenyaman suhu di dalam bangunan dengan memperhitungkan arah bukaan dan besar bukaan terhadapt arah matahari(Albatayneh, Alterman, Page, \& Moghtaderi, 2018). Bentuk bangunan tradisional seringnya menyesuaikan dengan iklim di dalam tapak sehingga menjadi menguntungkan mengambil inspirasi dari bangunan lokal (Desogus, Felice Cannas, \& Sanna, 2016). Penerapan aspek bangunan tradisional yang diterapkan pada bangunan dapat menjadi alternatif yang berbeda (Ragheb, El-Shimy, \& Ragheb, 2016).

\section{METODE PENELITIAN}

Metode yang digunakan adalah metode kualitatif melalui eksplorasi deskriptif (Maschinen, Investition, Beschaffungen, Ersatzbeschaffungen, \& Mittelherkunft, 2004) dan pemodelan. Data sekunder diperoleh dari selancar maya. Data tersebut terdiri dari bentuk tapak dan bangunan, orientasi bangunan, dan bentuk bangunan dan alam di sekeliling tapak. Kasus yang dieksplorasi terdiri dari Shijiazhuang International Convention and Exbibition Center, Flekekefjord Cultural Center, dan Sami Cultural Center Sajos. Pemodelan dilakukan di bangunan West Java Art and Cultural Center di Bandung, Jawa Barat. Variabel meliputi bentuk tapak, orientasi alam, dan bentuk bangunan dan Kawasan sekitar kasus. Data di analisis dengan membandingkan variable yang sama di ketiga kasus. Temuan di ketiga kasus didiskusikan dengan kajian tentang penerapan lokal. Hasil diskusi digunakan untuk menjelaskan pemodelan bangunan West Java Art and Cultural Center di Jalan Pahlawan, Bandung, Jawa Barat.

\section{HASIL PENELITIAN DAN PEMBAHASAN}

Bagian ini membahas tiga variabel yaitu inspirasi bentuk tapak, orientasi alam, dan bentuk setempat. Ketiga variabel tersebut dideskripsikan mulai dari temuan kemudian didetilkan per kasus.

\section{A. Inspirasi Bentuk Tapak}

Ketiga kasus bangunan memiliki bentuk tapak yang berbeda. Dua kasus yaitu Flekkeefjord Cultural Center dan Shijią̧uang International Convention and Exbibition Center berada di kawasan padat. Ketiga kasus menggunakan bentuk tapak sebagai inspirasi bentuk massa bangunan (lihat Gambar 1). Massa bangunan Flekkefjord Cultural Center berbentuk gabungan persegi panjang yang menyesuaikan dengan bentuk tapak. Penambahan bentuk segitiga yang terdistorsi memperlihatkan bentuk trapezium tapak. Tapak di sekitar bangunan Flekekefjord Cultural Center memiliki bentuk persegi panjang dengan susunan yang tidak teratur sehingga penerapan bentuk tapak juga diterapkan pada 
bangunan Flekkefjord Cultural Center. Massa bangunan Shijią̧uang International Convention and Exbibition Center sesuai dengan tapak yaitu berbentuk trapezium. Salah satu sisi tapak bangunan ini memiliki bentuk lengkung yang diakomodasi oleh bentuk lengkung massa bangunan. Kasus massa bangunan Sami Cultural Center Sajos meskipun tidak terlalu jelas namun juga menyesuaikan dengan bentuk tapak yang tidak beraturan. Penyesuaian bentuk massa bangunan dengan bentuk tapak menunjukkan kontekstual bangunan dengan kawasan sekitar. Kondisi ini mempertegas pendapat Fajrin \& Kurniawan (2018) yang menyatakan bahwa bentuk bangunan yang sesuai dengan tapaknya akan memperkuat lokalitas bangunan.
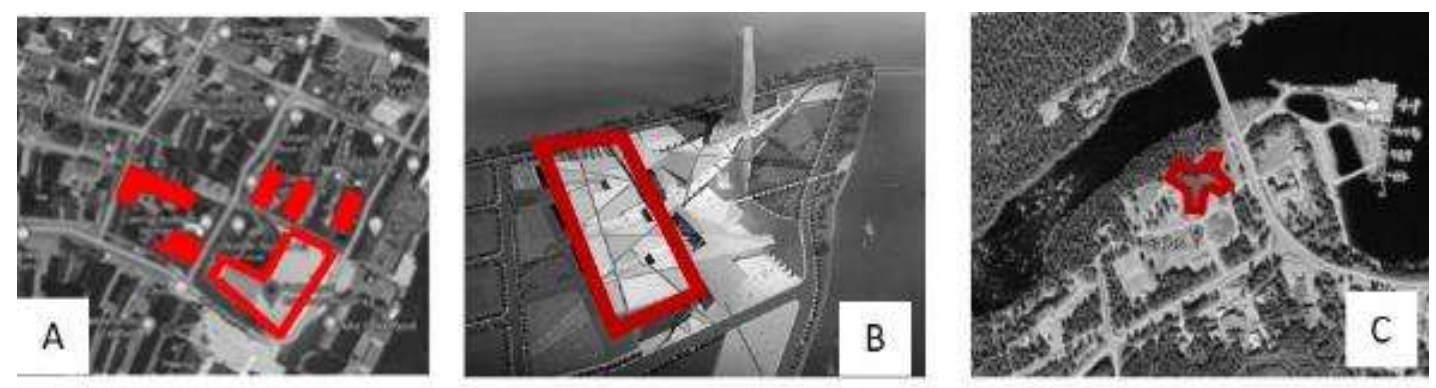

Gambar 1. Inspirasi Tapak (A: Flekkefjord CC; B: Shijiazhuang ICEC; C: Sami CCS

(Sumber: diolah dari google earth dan Council on Tall Building and Urban Habbit, n.d.)

\section{B. Inspirasi Orientasi Alam}

Ketiga kasus memiliki orientasi alam yang berbeda. Ketiga kasus memiliki perairan berupa sungai dan danau di dekat tapak sebagai orientasi bangunan (lihat Gambar 2). Flekkefjord Cultural Center memiliki orientasi bangunan menghadap pelabuhan di dekat tapak. Orientasi bangunan dipertegas dengan adanya material kaca pada arah pelabuhan sehingga pengunjung dapat langsung melihat dermaga dan perairan dari dalam bangunan Flekkefjord Cultural Center. Kasus Shijią̧huang International Convention and Exbibition Center memiliki bangunan yang berorientasi pada taman di utara tapak yang menghubungkan taman di dalam tapak dengan ruang terbuka hijau di sepanjang Sungai Hutuo sebagai tempat hiburan pada pengunjung dan warga sekitar. Penerapan orientasi alam pada bangunan Shijiashuang International Convention and Exbibition Center ini diaplikasikan berbeda dengan bangunan Flekkefjord Cultural Center yang ditunjukkan oleh material kaca, bangunan ini menunjukkan orientasi bangunan terhadap alam dari peletakan ruang terbuka hijau yang mengarah pada perairan berupa sungai di dekat tapak. Sami Cultural Center Sajos memiliki bangunan yang menghadap ke arah hutan dan danau di dekat tapak. Bangunan ini memiliki material façade kayu yang memaksimalkan orientasi ke arah hutan sehingga memberikan kesan bangunan yang menyatu dengan alam. Sami Cultural Center Sajos juga memiliki façade 
kaca yang transparan mengarah kepada Sungai Juutua. Letak bukaan pada bangunan yang searah dengan orientasi alam mendukung pendapat Albatayneh et al. (2018) yang menyatakan bahwa orientasi alam dapat mempengaruhi panas dan dingin bangunan dikarenakan bukaan yang menghadap ke arah tertentu.
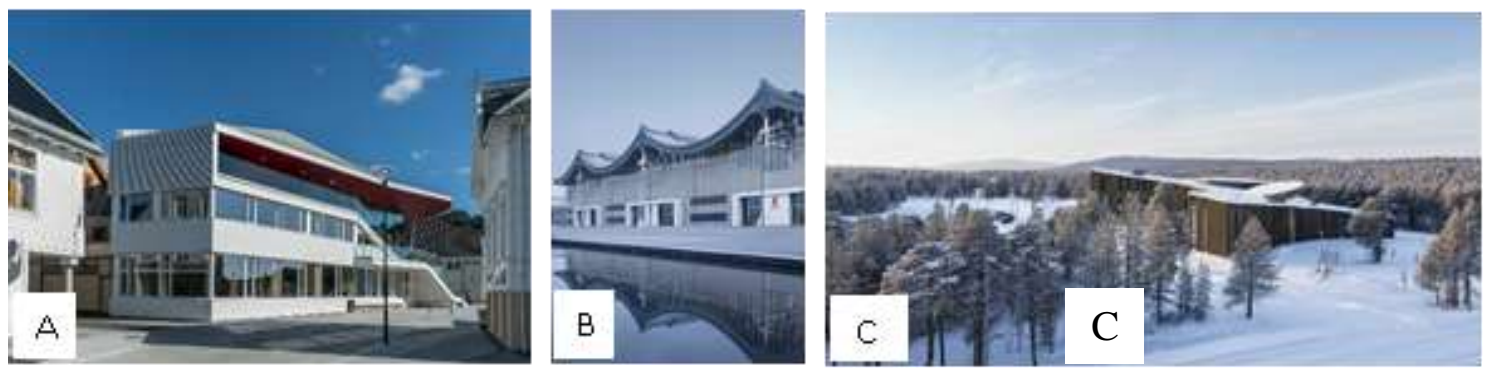

Gambar 2. Inspirasi Orientasi Alam (A: Flekkefjord CC; B: Shijiazhuang ICEC; C: Sami CCS

(Sumber: Arkitektur N, 2016; Council on Tall Building and Urban Habbit, n.d.; HALO Arkkitehdit Oy, 2012)

\section{Inspirasi Bentuk Setempat}

Ketiga kasus memiliki lingkungan yang memberikan inspirasi untuk bangunan tersebut. Inspirasi ini dapat diambil dari bangunan lain seperti bentuk dan atap bangunan ataupun lingkungan tertentu di dekat tapak bangunan seperti pepohonan dan sumber daya alam lain (lihat Gambar 3). Kasus Flekkefjord Cultural Center memiliki bentuk massa persegi panjang 2 lantai yang menyerupai bangunan lain di sekitarnya. Bentuk atap Flekekefjord Cultural Center ini berbentuk jurai agar serupa dengan bangunan lain di sekitarnya. Bentuk atap ini diberi modifikasi dengan peninggian dinding pada lantai 2 sehingga dari bawah bangunan akan terlihat memiliki atap yang datar. Flekkefjord Cultural Center ini juga memiliki warna putih dan bentuk bukaan yang menyerupai dengan bukaan bangunan lain disekitarnya sehingga bentuk bukaan menjadi lebih kecil daripada bangunan sejenis pada umumnya. Shijiazhuang International Convention and Exhibition Center memiliki bentuk atap berupa bangunan tradisional Cina yaitu atap Ngang Shan yang merupakan atap pelana yang memiliki kemiringan sedikit curam dan sedikit melengkung. Kasus bangunan Sami Cultural Center Sajos memiliki façade kayu yang terinspirasi dari lingkungan sekitarnya yang berupa hutan, sehingga pengaplikasian façade kayu secara vertikal dapat memberikan kesan bangunan yang berintegrasi dengan alam di sekitarnya. Ketiga bangunan ini memperkuat pendapat bahwa bangunan yang terinspirasi dari bangunan sekitar dan lingkungannya dapat memberikan kesan tersendiriterhadap bangunan tersebut. 

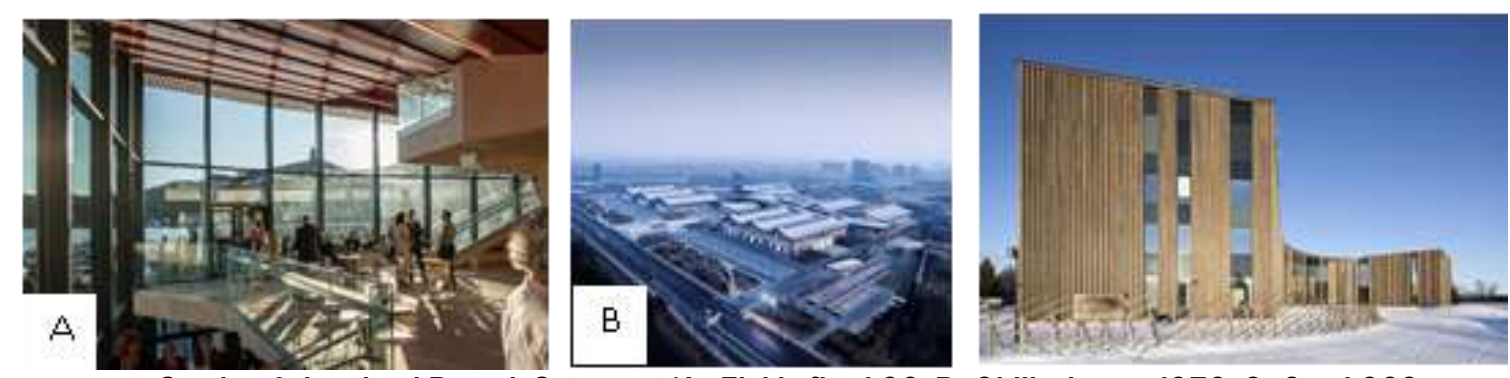

Gambar 3. Inspirasi Bentuk Setempat (A: Flekkefjord CC; B: Shijiazhuang ICEC; C: Sami CCS

(Sumber: Arkitektur N, 2016; Council on Tall Building and Urban Habbit, n.d.; HALO Arkkitehdit Oy, 2012)

Dari uraian diatas terlihat bahwa ketiga kasus yaitu Flekkefjord Cultural Center, Shijiazhuang International Convention and Exbibition Center, dan Sami Cultural Center Sajos memiliki respon tersendiri terhadap budaya di dalam kawasannya. Penerapan unsur lokal ke dalam bangunan dapat diaplikan pada seluruh aspek bangunan. Inspirasi arsitektur lokal di ketiga kasus dapat dibandingkan dan disimpulkan berdasarkan variable berikut.

Tabel 1. Nama Tabel

\section{Flekkefjord Cultural Center}

\section{Shijiazhuang \\ International \\ Convention and \\ Exhibition Center}

Tapak trapezium, massa bangunan trapezium

\section{Sami Cultural \\ Center Sajos}

Temuan

Tapak tidak beraturan, massa bangunan tidak beraturan
2 kasus: massa bangunan menyerupai bentuk tapak

\section{Bangunan menghadap taman yang mengarah ke sungai}

Bangunan
menghadap hutan \&
danau, material kaca
transparan \& kayu

Menghadap view alam (air, taman, hutan), material transparan \& material lokal
Fasad dengan kayu vertical agar sesuai dengan hutan disekitarnya.

\section{2 kasus penerapan setempat, 1 kasus penerapan unsur bangunan setempat}




\section{Penerapan Inspirasi Arsitektur Lokal Ke Bangunan Budaya di Bandung}

Berdasarkan uraian pada bagian sebelumnya, terdapat 3 variabel yang diterapkan di bangunan West Java Art and Cultural Center yang berlokasi di Bandung, Jawa Barat.. Inspirasi bentuk tapak diterapkan melalui bentuk bangunan yang merupakan modifikasi dari bentuk tapak yang berupa persegi panjang. Bentuk persegi panjang ini diberi lengkungan dan diberi pemisahan massa.

Penerapan bentuk tapak pada bangunan West Java Art and Cultural Center ini membuat massa bangunan memiliki bentuk massa-massa persegi panjang yang terpisah tapi terlihat saling terhubung. Bentuk dasar persegi panjang ini diberi modifikasi bentuk dengan tujuan menambahkan estetik tanpa menghilangkan identitas kawasan dikarenakan bangunan lain pada area bangunan West Java Art and Cultural Center ini juga memiliki bentuk massa bangunan yang terinspirasi dari bentuk tapaknya.

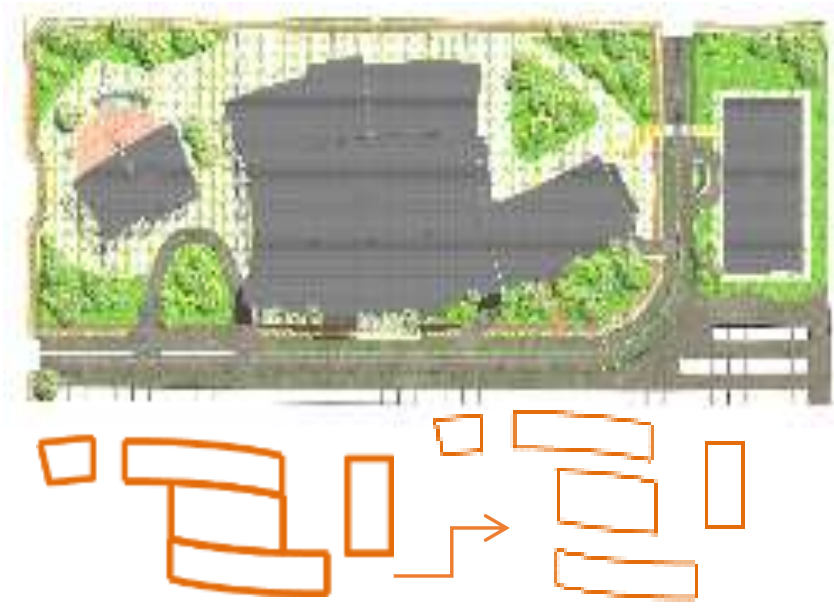

Gambar 3. Inspirasi Bentuk Tapak (Sumber: Data Pribadi, 2020)

Inspirasi orientasi alam diterapkan oleh bangunan West Java Art and Cultural Center pada penggunaan material transparan berupa kaca pada badan bangunan. Penggunaan material kaca ini berada pada seluruh badan bangunan dengan beberapa bagian yang ditonjolkan. Bagian utama yang di yang ditonjolkan adalah pada bagian barat bangunan dimana bagian ini mengarah pada area Makam Pahlawan Cikutra sehingga dari dalam bangunan West Java Art and Cultural Center pengunjung dapat melihat tugu makam yang menjadi simbol makam tersebut (lihat Gambar 4). Pada sisi lain bangunan material kaca diaplikasikan dengan mengarah pada ruang terbuka di luar bangunan West Java Art and Cultural Center sehingga dari dalam bangunan pengunjung dapat melihat pemandangan ruang terbuka dan vegetasi. 


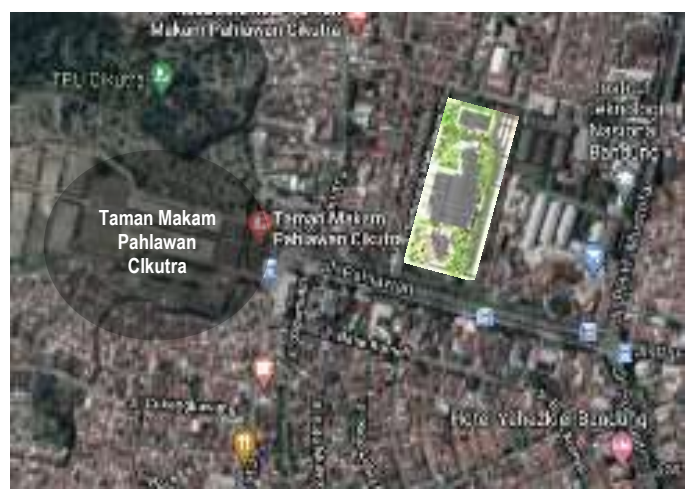

Gambar 4. Inspirasi Bentuk Orientasi Alam (Sumber: Data Pribadi, 2020)

Inspirasi bentuk setempat diterapkan melalui penggunaan atap bangunan yang terinspirasi dari atap Jolopong yang merupakan atap khas Jawa Barat. Atap Jolopong ini dipilih dikarenakan makna atap ini sendiri ada sebagai pengingat keselarasan hidup antara Tuhan, alam, dan juga manusia (Nuryanto, 2019). Atap ini berbentuk pelana dengan tambahan elemen garis menyerupai tanda silang pada puncak atapnya. Pada garis yang menyerupai tanda silang tersebut diberi modifikasi dengan perbedaan ketinggian dan diberi penambahan elemen kaca pada salah satu sisinya sehingga memberikan kesan modern pada bangunan (lihat Gambar 5). Di dalam tapak juga terdapat ruang pertunjukan outdoor yang memiliki panggung dan perkerasan sebagai area berkumpul. Panggung ini juga mengadopsi bentuk atap Jolopong pada panutup atap panggung dengan bentuk dasar pelana yang terbuka pada satu sisi sementara pada sisi lainnya dibuat tertutup.

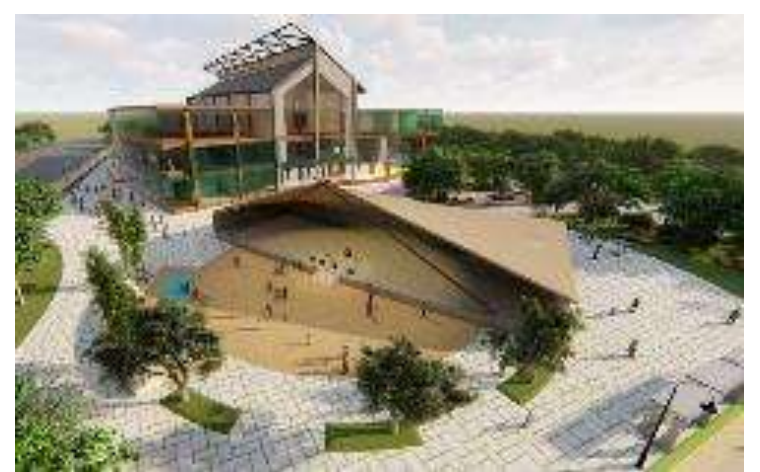

Gambar 5. Inspirasi Bentuk Setempat (Sumber: Data Pribadi, 2020)

\section{SIMPULAN}

Inspirasi arsitektur lokal terhadap bangunan budaya dapat diterapkan pada bentuk tapak, orientasi alam, dan penerapan bentuk setempat ke dalam bangunan. Dari ketiga kasus yang 
merupakan bangunan tipologi convention, exbibition, art, dan juga cultural center yaitu Flekekefjord Cultural Center, Shijiazhuang International Convention and Exhibition Center, dan Sami Cultural Center Sajos dapat dilihat bahwa ketiga kasus ini berhasil menjadi inspirasi bagi penerapan lokalitas ke dalam bangunan budaya modern.

Hasil dari penelitian ini adalah penerapan inspirasi bentuk tapak bangunan sesuai dengan bentuk tapak diterapkan oleh ketiga kasus dimana 2 kasus memiliki massa sesuai dengan bentuk tapak pada bangunan Flekkefjord Cultural Centerdan Shijiazhuang International Convention and Exbibition Center dan kasus Sami Cultural Center Sajos memiliki bentuk massa tidak beraturan seperti tapaknya. Penerapan inspirasi orientasi alam diterapkan pada ketiga kasus sehingga ketiga kasus memiliki orientasi terhadap air pada kasus Flekkefjord Cultural Center dan Sami Cultural Center Sajos, kasus berorientasi pada taman diterapkan oleh Shijiazhuang International Convention and Exbibition Center, kasus orientasi pada hutan diterapkan oleh kasus Sami Cultural Center Sajos yang juga menggunakan material transparan dan juga material lokal. Inspirasi bentuk lokal diterapkan oleh ketiga kasus, kasus Flekekefjord Cultural Center dan Shijiazhuang International Convention and Exbibition Center menerapkan bentuk lokal pada bangunannya dan kasus Sami Cultural Center Sajos yang menerapkan inspirasi bentuk setempat pada façade bangunannya yang disesuaikan dengan lingkungannya.

Inspirasi penerapan ketiga variabel ini dapat diterapkan pada bangunan lain seperti halnya pada bangunan West Java Art and Cultural Center ini. Inspirasi bentuk tapak diterapkan pada bentuk massa bangunan yang berbentuk persegi panjang sesuai dengan bentuk tapak dengan diberi modifikasi. Inspirasi orientasi alam diterapkan pada penggunaan material transparan yang berorientasi pada keunggulan lokal di dekat tapak. Inspirasi bentuk setempat diterapkan pada atap bangunan pada tapak baik bangunan utama West Java Art and Cultural Center maupun bangunan pendukung di dalam tapak. Atap bangunan pada tapak diinspirasi oleh atap bangunan lokal yang bentuknya diterapkan pada bangunan dan diberi modifikasi. Seluruh penerapan ini memberikan lokalitas bangunan budaya ke dalam bangunan modern dengan memasukkan unsur bangunan lokal ataupun unsur alamiah ke dalam bangunan modern dengan menjadikan unsur bangunan ataupun unsur alam tersebut sebagai inspirasi bentuk, orientasi bangunan, bahkan penerapan material di dalam bangunan.

\section{REFERENSI}

Albatayneh, A., Alterman, D., Page, A., \& Moghtaderi, B. (2018). The significance of the orientation on the overall buildings thermal performance-case study in Australia. Energy Procedia, 152, 372 377. https://doi.org/10.1016/j.egypro.2018.09.159

Arkitektur N. (2016). Flekkefjord Cultural Centre Spira, Flekkefjord. Retrieved from 
https://architecturenorway.no/projects/culture/Flekkefjord_Cultural_Centre_Spira_2016/

Council on Tall Building and Urban Habbit. (n.d.). Shijiazhuang International Convention \& Exhibition Center. Retrieved from https://www.skyscrapercenter.com/building/shijiazhuanginternational-convention-exhibition-center/9616

Dabaieh, M., Makhlouf, N. N., \& Hosny, O. M. (2016). Roof top PV retrofitting: A rehabilitation assessment towards nearly zero energy buildings in remote off-grid vernacular settlements in Egypt. Solar Energy, 123, 160-173. https://doi.org/10.1016/j.solener.2015.11.005

Desogus, G., Felice Cannas, L. G., \& Sanna, A. (2016). Bioclimatic lessons from Mediterranean vernacular architecture: The Sardinian case study. Energy and Buildings, 129, 574-588. https://doi.org/10.1016/j.enbuild.2016.07.051

Fajrin, H. N., \& Kurniawan, R. (2018). Gedung Pertunjukan Musik Dengan Penekanan Arsitektur Kontemporer. Sigma Teknika, 1(1), 49. https://doi.org/10.33373/sigma.v1i1.1394

HALO Arkkitehdit Oy. (2012). Sámi Cultural Center Sajos. Retrieved from https://archello.com/project/sami-cultural-center-sajos

Kırbaş, B., \& Hızlı, N. (2016). Learning from Vernacular Architecture: Ecological Solutions in Traditional Erzurum Houses. In Procedia - Social and Behavioral Sciences (Vol. 216, pp. 788-799). https://doi.org/https://doi.org/10.1016/j.sbspro.2015.12.076

Maschinen, B., Investition, A., Beschaffungen, G., Ersatzbeschaffungen, B., \& Mittelherkunft, S. (2004). Research Methodology.

Mehrabi, M. (2016). Consideration of Climate Impact on Contextual Architecture in Arid Regions. The Turkish Online Journal of Design, Art and Communication, 6(AGSE), 2011-2018. https://doi.org/10.7456/1060agse/079

Nuryanto, M. T. (2019). Arsitektur Nusantara.

Ragheb, A., El-Shimy, H., \& Ragheb, G. (2016). Green Architecture: A Concept of Sustainability. Procedia - Social and Behavioral Sciences, 216(October 2015), 778-787. https://doi.org/10.1016/j.sbspro.2015.12.075

Shareef, V. A., Omer, S. K., \& Maghdid, H. S. (2020). Impact of Building Orientation on Market Value: Koya municipality as a case study. Qalaai Zanist Scientific Journal, 5(1). https://doi.org/10.25212/lfu.qzj.5.1.08

Wang, Y., Li, X., \& Gan, Y. (2016). Study on the Green Design Strategies of "neo-Vernacular Architecture." Procedia Engineering, 169, 367-374. https://doi.org/10.1016/j.proeng.2016.10.045 